\title{
Second Language Listening Comprehension Gain From Aural vs. Audio-Visual Inputs: The Case of EFL Arab Learners
}

\author{
Anwar A. H. Al-Athwary \\ College of languages and Translation, Najran University, Saudi Arabia \\ Nada M. Lasloum \\ College of languages and Translation, Najran University, Saudi Arabia
}

\begin{abstract}
This study aims at finding out which medium is best for the acquisition of $\mathrm{L} 2$ listening skills, aural or audio-visual listening comprehension. Sixty EFL Arab learners were asked to sit for pre- and post-tests. The post-test proved a significant improvement in the performance of the students of the experimental group who were exposed to audio-visual medium. This outperformance of the experimental group appeared in their ability to distinguish the meanings of several words in the pre- and post-tests. They were able to identify most of the L2 vocabulary, grammar and syntax because of using the audio-visual materials. The experimental group managed to understand the linguistic information and they were also able to answer the questions in both given tests correctly. On the contrary, the performance of the control group was clearly poor in terms of the $\mathrm{L} 2$ vocabulary, grammar and syntax and the reason is referring to the use of the traditional material which is the aural one. The subjects of the experimental group were interested in learning listening by using audio-visual materials because it helps them to develop the listening skills faster, unlike the subjects of the control group. Therefore, the results show that multimedia is effective in enhancing the skills of listening comprehension of female Saudi EFL learners.
\end{abstract}

Index Terms - audio-visual, aural, EFL learners, L2 listening comprehension

\section{INTRODUCTION}

\section{A. Aural vs. Audio-Visual Listening Comprehension}

In aural listening comprehension, a listener receives comprehensible input aurally and he/she is required to internally interact in order to reconstruct or analyze the received input. Bacon (1992) and Scarcella and Oxford (1992) explain that during the timeline of FL listening comprehension, aural listening comprehension is always relatable to the term "authentic materials" which according to Rogers and Medley (1988) refers to "language samples that reflect a naturalness of form, and an appropriateness of cultural and situational context that would be found in the language as used by the native speakers" (p. 468). In other words, it is the language that L2 natives produce in oral interactions. On the other hand, audio-visual listening helps improve EFL learners' listening skills by providing both linguistic and cultural inputs; listeners select and interpret information which comes from auditory and visual cues in order to define what is going on and what the speakers are trying to express. Buck (2001) explains that the audio-visual listening mean is that one where students can watch the theme and hear the speech at the same time. This mean is helpful for weak EFL students because it simplifies difficult listening comprehension. Regarding to that, Lever-Duffy (2003) shows that the audio-visual mean has many advantages because both senses (sight and hearing) of EFL students are motivated and construct many perceptual interactions to the given audio-visual comprehension. This advantage of the audio-visual material simplifies learning L2 as it satisfies the learners expectations including those ones who have different strategies for the listening skill.

\section{B. Factors Hindering Listening}

There are some problems that may hinder listening comprehension because it is a complex process that requires learners to adopt an active role to encode listening input. Nushi and Orouji (2020) report a number of general factors lying behind listening difficulty. These include speech speed of delivery of texts, lexical coverage, limited capacity of short-term, lack of prior knowledge, and high levels of anxiety. Similarly and in some more detail, Dunkel (1991) points out that there are eight factors which hamper the efficiency of listening comprehension on the part of EFL/ESL learners, namely speed, repetition of words, poor vocabulary knowledge, unawareness of discourse markers, lack of contextual knowledge, lack of concentration in a foreign language, learning habits and interaction. First, while listening, EFL learners should learn how to divide language chunks or clusters into small groups of words in order to overcome speed speech. Second, repetition of words or redundancy gives EFL learners further time in order to process and construct meaning of the spoken language. Therefore, EFL learners may face difficulty in listening comprehension 
when there is a little redundancy in the listening passage. Third, EFL learners may face difficulty in listening comprehension as well if they are not aware of the reduced forms which frequently occur in the spoken language. These reduced forms may occur phonologically, syntactically, semantically or pragmatically. Fourth, EFL learners should be trained to identify the functions of discourse markers like adverbs and different types of conjunctions when constructing meaning of the spoken language. Fifth, EFL learners should be aware of the cultural values and norms that determine the communicative functions of the spoken language in different social situations and the goals behind such utterances. Sixth, EFL learners should be trained to have full concentration while practicing different modes of listening such as aural, audio or audio-visual. Seventh, EFL learners should be trained to use different listening strategies. These strategies include detection of key words, guessing the most probable meaning of unknown words from the context and identifying main and minor ideas, hypotheses and generalizations. Eighth, EFL learners should be aware that the main purpose behind listening comprehension is to train them to interact and become good responders who can negotiate meaning.

\section{Top-Down and Bottom-Up Listening Strategies}

As other language skills, listening is acquired by following different learning strategies. Bueno, Madrid and Mclaren (2006) indicate that the L2 listening process has two basic strategies: top-down and bottom-up listening strategies. As for the top-down listening strategy, it involves recognizing the major core of the speech in the comprehension generally, regardless concentrating on the meaning of each word or each sentence. On the other hand, the bottom-up listening strategy has a linguistic identity that stresses the usage of the linguistic knowledge of the L2 for the learners. The L2 linguistic background entails recognizing the L2 sounds and words like, for example, being able to distinguish the homophones as in 'flower' and 'flour'. In addition, the L2 learner should be able to recognize the types of syllables like the closed syllable as in 'test' and the leftovers syllable as in 'cottage' in order to identify the words. L2 learners should also have a sufficient knowledge about parsing to get acquainted to the hierarchical structure of the sentences. They are also supposed to update their stored information of the L2 to the new inputs, because this step helps in having a full understanding of the new knowledge in any given spoken text. It is also necessary to use both listening strategies (topdown and bottom-up) in the listening process because skipping one of them will lead to a failure in the performance. Such learners have a pre-idea about what they will hear and cannot change that idea along with the listening text. They tend to overlook information contrary to their background information; they make inferences based on their background knowledge and avoid understanding the new information. Those learners usually fail to define the end of words as they cannot divide the speech stream into sound units. They also go through difficulty in defining word boundaries when L2 stress patterns differ from those of their L1. Thus, they fail in analyzing, evaluating facts and causes included in the listening text.

Rost (2002) asserts that both terms are mainly meant to reflect on how a listening text is processed by EFL/ESL learners through certain strategies and learning techniques. Both terms are viewed as two different separate strategies adopted by EFL/ESL learners in order to process and comprehend a listening text. Top-down listening strategies specifically refer to a general outlook of a certain listening text which reflects its meaning in general. Such top-down strategies usually start with a general discussion of the topic prior to using an extensive task which reflects the comprehensive meaning of the intended listening task. According to Lynch and Mendelsohn (2002), top-down strategies depend on EFL/ESL learners' knowledge about the topic being listened to, their knowledge of the appropriateness of using language chunks and expressions in different situations, and their knowledge of different language functions in various social situations. On the contrary, Brett (1995) explains that bottom-up listening strategies differ from top-down strategies in their focus on understanding the details of the intended listening task including sounds and words. Whereas top-down strategies are adopted when listening to a mother-tongue listening comprehension, it is likely that EFL/ESL learners adopt bottom-up strategies when listening to an English listening task. They attempt to understand every detail and word in the text. Thus, according to Underwood (1990), EFL/ESL learners may desperately fail in understanding all words and details included in the intended listening task. They may account their failure on the basis of English language speed speech, which is faster, from their view, than their first languages including Arabic. However, this justification is virtually untrue because even for an English man learning Arabic, for example, he could consider Arabic as fast language. The point is that every language is spoken at a certain speed, and it is the brain which mainly responsible for processing each word included in the intended listening task. It could be hardly difficult for the brain to process each single English word. This cognitive failure is the main reason of why EFL/ESL learners consider listening as a difficult task. This does not simply mean that EFL/ESL learners should be only trained to use top-down strategies even though such strategies are useful as a kick-start of comprehending an overall gist of the intended listening task.

Therefore, as much as EFL/ESL learners are in need to focus on developing top-down strategies, they cannot totally ignore the bottom-up strategies. It is totally mistaken for EFL/ESL learners to believe that they can rely on a single listening strategy. For instance, they cannot process a listening task from a general meaning view (i.e. top-down strategies) or from a detail-based view (i.e. bottom-down strategies). Therefore, Field (2002) states that it is inevitable for EFL/ESL learners to use both strategies while listening to a target language listening task. For instance, when an EFL/ESL learner only picks up a few words of the listening task, he/she becomes interested in the whole listening text. In such a case, a learner will attempt to reconstruct the fragments of sentences. Using both strategies of top-down and 
bottom-up, according to Nunan (1992), will help such a learner comprehend the listening task. Therefore, EFL/ESL learners should keep a balanced approach which combines both types of listening strategies: top-down and bottom-up.

\section{The PRESENT StUdy AND ResEARCH Questions}

EFL learners in general and EFL learners of Najran University in particular face many difficulties in listening comprehension. In light of the above-mentioned factors and strategies pertaining to the skill of listening, the present study attempts to find out which medium is better for acquiring better listening, the aural medium or the audio-visual medium. To the best of researchers' knowledge, there is no study conducted on this topic at Najran University. Therefore, it is felt necessary to examine the ability of Saudi EFL learners at the level of university in two different types of listening comprehension, namely aural and audio-visual. The present study collects data based on two different types of listening comprehension tests: aural test and audio-visual test.

This study investigates the L2 listening skills acquisition among EFL Arab learners, namely female EFL Saudi students at Najran University. The proper aim of this study is to investigate which medium is best for the acquisition of L2 listening skills, aural or audio-visual listening comprehension. This investigation holds a comparison between aural and audio-visual listening activities in terms of a number of L2 listening variables. They include L2 vocabulary knowledge, understanding the linguistic information, auditory discrimination, and guessing the meaning of unknown vocabulary. In other words, the current study attempts to find answer to the following research questions:

1. How likely do the Saudi female EFL learners vary in their knowledge of L2 vocabulary?

2. To what extent do they differ in grasping the linguistic data occurred in the given listening comprehension?

3. How likely do they apply the different ways of discrimination and guessing of unknown words?

\section{The CONCEPTUAL FRAMEWORK OF THE StUDY}

The theoretical framework of this study is based on learners' L2 variables devised by both Vandergrift and Baker (2015) and on Mayer's (2001) cognitive theory of multimedia learning. As to learners' L2 variables, the present study excludes the first variable of L1 vocabulary knowledge because it is not highly applicable to Arabic and English. This variable is mainly meant to transfer L1 lexical knowledge into L2 listening when the two languages are highly related to each other, e.g. French and English. Instead, the current study is theoretically based on the other variables of learners' L2, namely L2 vocabulary knowledge, metacognition, working memory, and auditory discrimination. L2 listening test is devised and analyzed in terms of Vandergrift and Baker's (2015) learners' L2 variables.

Vandergrift and Baker (2015) examine the effect of the L2 student's variables on the L2 listening comprehension. The variables include the L1 and L2 vocabulary; the listening comprehension of L1; the sufficient ability of recalling and the audial reorganization. Moreover, they investigate how the student's cognitive variables involve in the L2 listening comprehension. The data were gathered by French and English listening comprehension tests. These tools are for analyzing the L1 and the L2 listening comprehension. The authors used the Peabody Picture Vocabulary Test in its fourth edition in order to measure the knowledge of L1 and L2 vocabulary. The Pimsleur Language Aptitude Battery (Pimsleur, Reed, and Stansfield, 2004) was adopted in order to measure auditory discrimination. Vandergrift and Baker use a self-report which is called the Metacognitive Awareness Listening Questionnaire including twenty-one items related to the procedures and methods of L2 listening comprehension. The procedures and methods entail working out problems, preparing and assessment, intellectual translation, informational background, as well as instructed attentiveness. Taking part in the study was carried out on voluntarily basis where participants and their parents had to give their consent. Vandergrift and Baker indicate that all the students' expected variables were confirmed as favorable signs of the L2 listening comprehension. Remarkable statistical correlation coefficients appeared to prove the favorable interactions between students' L2 vocabulary, L1 variables, L1 listening comprehension, audial reorganization and the sufficient ability of recalling as well as the students' L2 listening comprehension skills.

As to L2 vocabulary knowledge, Field (2003) clarifies that EFL learners may not be able to identify L2 words because of the rapid speech. This failure on the part of L2 learners does not, however, underestimate the contribution of L2 vocabulary knowledge to the success of L2 listening process as Mecartty (2000) finds that knowledge of L2 vocabulary, grammar and syntax contribute by $14 \%$ to enhance L2 learners' listening skills. Staehr (2009) proves that the L2 listening test scores of Danish learners are correlated to their L2 vocabulary size and depth; L2 vocabulary knowledge accounts for $51 \%$ of the listening differences among Danish participants, where $49 \%$ explains L2 listening difference in terms of participants' vocabulary size while $2 \%$ of that difference is attributed to vocabulary depth. Bonk (2000) and Zeeland and Schmitt (2013) highlight the considerable effect of L2 vocabulary knowledge on L2 listening variation because L2 learners vary in their management of the words which they know and those which they are not sure of their meanings while listening to an L2 listening task. This variation is mainly attributed to their different metacognitive abilities. In this context Brett (1997) explains "listening assumes increased importance as not only it is a key language and communication skill in its own right, but it also provides a channel through which new language can be received and may become intake" (p. 39).

As to metacognition, Goh (2008), and Vandergrift and Goh (2012) explain that metacognition reveals the cognitive strategies which L2 listeners use in order to comprehend the listening task; these strategies include controlling, 
regulating and directive the cognitive processes of comprehension. In this regard, Graham and Macaro (2008) attribute better performance in L2 listening to the cluster of L2 listeners' cognitive strategies. For instance, in their argument of listening to learn versus learning to listen, Vandergrift and Cross (2018) believe that it is not enough to listen to learn but learners should learn how to listen in an L2; it refers to a pedagogical tendency towards addressing the process of learning and how students arrive at comprehension (p. 1).

As to working memory, Juffs and Herrington (2011) emphasize that L2 learners vary in their learning and use of an L2; that is their retention of L2 phonological information related to L2 sounds and their processing of visual and spatial information. Andringa, Olsthoorn, van Beuningen, Schoonen, and Hulstijn (2012) find statistically insignificant relationship between L2 listening ability of Dutch learners and their working memory.

As to auditory discrimination, just like the little evidence on the correlation between L2 listeners' working memory and their success in an L2 listening task, little is known about the relationship between L2 listeners' auditory discrimination and L2 listening success. In this concern, Wilson, Kaneko, Lyddon, Okamoto, and Ginsburg (2011) affirm the statistically significant relationship between L2 listeners' ability of auditory discrimination and their success in L2 listening.

As to the cognitive theory of multimedia learning of Mayer (2001), its main components are: (1) visual and auditory structures, (2) little capacity of processing available in the memory, (3) sensory, working and long-term memory stores, (4) cognitive ability to select words and images, organize work and images, and integrate newly acquired knowledge with the stored knowledge. Participants' responses to the 14-item questionnaire are analyzed in terms of these components. Mayer (2009) asserts that the first, third and fourth components of the cognitive theory of Multimedia learning help realize meaningful learning. Brett (1997) finds "there may be certain gains in efficiency of the use of a computer interface for all of the components of listening tasks. Responses to question 4 seem to indicate that learners feel that such an amalgamation helps make listening easier. It was certainly noticeable during the video plus pen and paper tasks that over half of the learners in each class never watched the video but only looked at the written true/false statements on their task papers" (p. 48).

\section{RESEARCH METHODS}

\section{A. Research Design}

The present study adopted the design of the quasi-experimental research. Two types of tests, namely pre-test and post-test, were employed for both the control group and the experimental group. Some of the subjects selected for the study were assigned to the experimental group while the others were assigned to the control group. Both experimental and control groups sat for the listening pre-test. Then, the experimental group was taught on watching and listening using audio-visual listening materials whereas the control group was taught listening using aural listening materials only. Finally, the experimental group appeared for watching and listening post-test based on the audio-visual materials while the control group sat for the same test but on the basis of using aural listening materials only. The listening post-test aims to determine statistically significant differences between the experimental and control groups in terms of the four dependent variables: subjects' knowledge of L2 vocabulary, metacognition, working memory and auditory discrimination.

\section{B. Participants}

A cluster random sampling technique was used to select sixty female EFL students. The participants are in the firstyear level at the Department of English, College of languages, Najran University. A consent form was distributed to the subject to confirm that they agree to participate in the tests. The sample was further divided into two groups, namely experimental group and control group with each group having thirty subjects. In addition, more ten female students were selected for the pilot study.

\section{Materials}

The materials meant for the test instrument were ten short English conversations. They were extracted from an English learning program called "Living English" broadcast on ABC Australia TV channel (formerly known as Australia Plus). The episodes of the program are also available on the website: http://www.abc.net.au/education/learnenglish/ and also on YouTube (https://www.youtube.com/playlist?list=PLqmHbm3J8Fw1JYCdFQpgrEr8adJ3q-JWv). The average duration of each conversation is one minute and thirty seconds. The conversation content is designed for beginners and those who have basic English skills. Therefore, such conversations are appropriate to the level of participants whose proficiency in English doesn't exceed the level of beginners. The variable-based questions of the test were constructed based on the content of the conversation as shown in the next sub-section.

\section{Listening Test}

The instrument of data collection in this study was a listening test. It consisted of a pre-test and a post-test. The two listening tests were derived from activities included in the episodes of Living English program. Before administering the test, the participants were exposed to the listening activities during the experimental period. This helped subjects to recall situations in which the tested items occurred in a way that could remind them of the correct answers. Each type of 
the listening test contained five questions each. They were devised in order to know the effect of the independent variable (aural or audio-visual materials) of the present study on the dependent variables (subjects' knowledge of L2 vocabulary, metacognition skills, working memory, and discrimination of sounds). As the materials of both listening pre- and post-tests were derived from a reputable website which is taught worldwide at different English Language schools and language centers, both pre- and post-listening tests can be judged as valid and reliable. In this particular case, the need to pilot the two listening pre- and post-tests did raise. In order to assess the reliability of pre- and posttests in Appendices A and B, a pilot study was conducted on ten female students and calculated by the Cronbach Alpha.

\section{Data Analysis AND Results}

Theoretically, the data were analyzed based on the interrelationship between the variables. The analysis of data also relied on the cognitive theory of multimedia learning as introduced by Mayer (2001). The current study, then, adopted the t-test, paired samples statistics test and Pearson correlation analysis to decide if there was a remarkable statistical difference between the subjects' performance the control group and the experimental one, on the one hand, and indicated the effect of using audio-visual and aural listening materials on the subjects' performance, on the other. The statistical significance was determined at the level of $\mathrm{P}>.05$.

The reliability coefficient of the research tool administered (i.e., the test) was computed by using Cronbach's alpha. Table 1 displays the values of reliability for both tests (pre- and post-test) while Table 2 reveals values of Alpha Cronbach for each test. All the outputs were elicited from the SPSS version 21.

TABLE 1

RELIABILITY STATISTICS

\begin{tabular}{lll}
\hline Cronbach's Alpha & Cronbach's Alpha Based on Standardized terms & N of Items \\
\hline .925 & .926 & 2 \\
\hline
\end{tabular}

TABLE 2

ITEM-TOTAL STATISTICS

\begin{tabular}{llccc}
\hline Test & $\begin{array}{l}\text { Scale Mean if ItemScale Variance } \\
\text { Deleted }\end{array}$ & if $\begin{array}{c}\text { ItemCorrected } \\
\text { Correlation }\end{array}$ & $\begin{array}{c}\text { Item-TotalSquared } \\
\text { Correlation }\end{array}$ & Multiple \\
\hline pre-test & 67.0000 & 879.831 & .863 & .744 \\
\hline Post-test & 63.5833 & 748.383 & .863 & .744 \\
\hline
\end{tabular}

As Table 1 shows, the reliability coefficient is .92 , which deems high. It indicates that the internal consistency of the tests items is high. Therefore, the values of the total items of both tests collectively and the values for each test as separate indicate a strong internal consistency of the items. As a result, this leads to the possibility of generalizability of the findings of the current study.

To discover the most effective channel to aid listening comprehension, means, standard deviation, skewness, and kurtosis were computed. Table 3 and Figure 1 summarize all the statistics for the experimental group while Table 4 and Figure 2 reflect the achievements of the control group.

TABLE 3

DESCRIPTIVE STATISTICS FOR THE EXPERIMENTAL GROUP $(\mathrm{N}=30)$

\begin{tabular}{llllll}
\hline No. & Variables & M & SD & Minimum & Maximum \\
\hline 1 & pre-test & 87.8 & 8.9 & 10 & 100 \\
\cline { 2 - 6 } 2 & Post-test & 93.3 & 10.1 & 20 & 100 \\
\hline
\end{tabular}

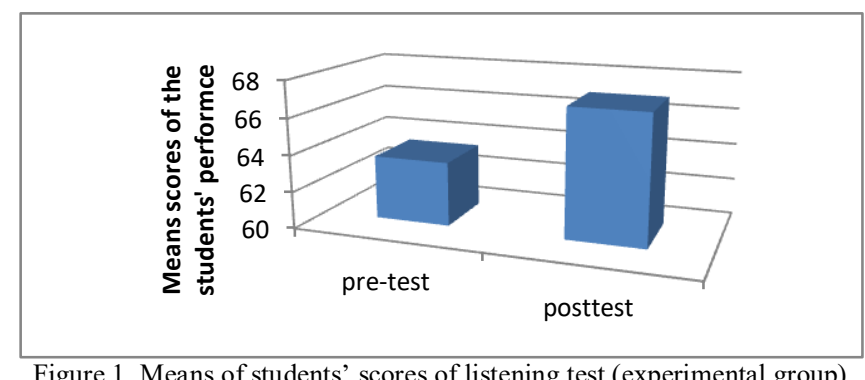

Figure 1. Means of students' scores of listening test (experimental group)

As shown in Table 3 and Figure 1, the students got improved from time 1 (pre-test) $(\mathrm{M}=87.8, \mathrm{SD}=8.8)$ to time 2 (post-test), gaining $(M=93.3, S D=10.1)$. This indicates the positive effects of exposure to the treatment of audio-visual mode that delivered listening comprehension skills.

Regarding the listening comprehension delivered by the audio tracks mode, mean scores of the students as shown in Table 4 and Figure 2 indicated that the students also got a slight improvement in listening comprehension skills when engaged in audio mode (the improvement from a pre-test $(M=39.3 S D=15.0)$ to the post-test $(M=40.6, S D=15.8)$ ). 
TABLE 4

DESCRIPTIVE STATISTICS FOR THE CONTROL GROUP $(\mathrm{N}=30)$

\begin{tabular}{llllll}
\hline No. & Variables & M & SD & Minimum & Maximum \\
\hline 1 & pre-test & 39.3 & 15.0 & 10 & 100 \\
\hline 2 & Post-test & 40.6 & 15.8 & 20 & 100 \\
\hline
\end{tabular}

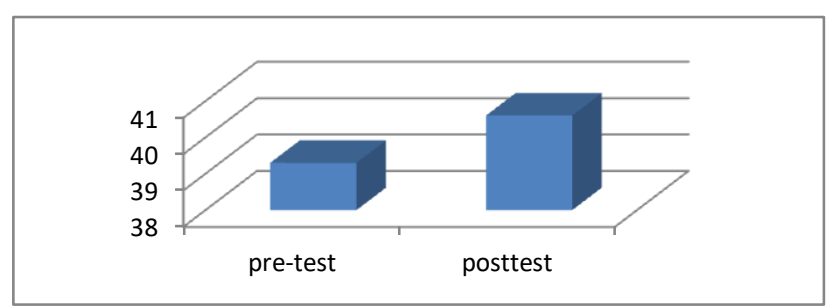

Figure 2. Means scores of the control group students

Concerning whether there was a statistically significant difference between the achievements of both groups in terms of both tests, a t-test was performed. The results of the t-test indicated that the differences between the students' scores in both tests are significant. Means of the audio-visual group students $(\mathrm{M}=63.0, \mathrm{SD}=27.3)$ were significantly higher than the means of the audio group $(M=67.0, S D=29.6), t(58)=15.1, p=.000, d=.12)$. This indicates that the audio-visual technique was the best mode to aid L2 listening skills.

TABLE 5

MEANS SCORES FOR BOTH GROUPS

\begin{tabular}{llll}
\hline Group & \multicolumn{3}{c}{ MEANS SCORES FOR BOTH GROUPS } \\
\hline \multirow{2}{*}{ Experiment } & Mean & pre-test & Post-test \\
\cline { 2 - 4 } Control & Std. Deviation & 87.8 & 93.3 \\
\hline \multirow{2}{*}{ Total } & Mean & 8.9 & 10.1 \\
\cline { 2 - 4 } & Std. Deviation & 39.3 & 40.6 \\
\hline & Mean & 15.0 & 67.0 \\
\hline
\end{tabular}

TABLE 6

INDEPENDENT SAMPLES TEST

Levene's Test for t-test for Equality of Means

Equality of

Variances

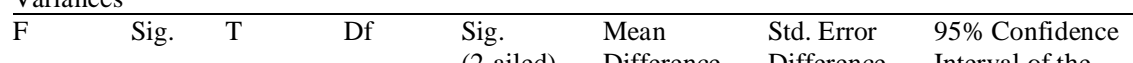

(2-ailed) Difference Difference Interval of the

Difference

\begin{tabular}{|c|c|c|c|c|c|c|c|c|c|c|}
\hline & & & & & & & & & Dimtere & \\
\hline & & & & & & & & & Lower & Upper \\
\hline Drestect & $\begin{array}{l}\text { Equal variances } \\
\text { assumed }\end{array}$ & 12.18 & .001 & 15.189 & 58 & .000 & 48.50 & 3.19 & 42.10 & 54.89 \\
\hline 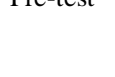 & $\begin{array}{l}\text { Equal variances } \\
\text { not assumed }\end{array}$ & & & 15.189 & 47.36 & .000 & 48.50 & 3.19 & 42.07 & 54.92 \\
\hline Post_test & $\begin{array}{l}\text { Equal variances } \\
\text { assumed }\end{array}$ & 3.71 & .059 & 15.304 & 58 & .000 & 52.66 & 3.4 & 45.77 & 59.55 \\
\hline Fost-test & $\begin{array}{l}\text { Equal variances } \\
\text { not assumed }\end{array}$ & & & 15.304 & 49.49 & .000 & 52.66 & 3.44 & 45.75 & 59.58 \\
\hline
\end{tabular}

To measure if female EFL learners statistically significant vary in their knowledge of L2 vocabulary, Paired Samples Statistics test for the two groups was carried out in Post-Test. Table 7 indicates the results:

TABLE 7

PAIRED SAMPLES STATISTICS TEST (POST-TEST) L2 VOCABUlary

\begin{tabular}{|c|c|c|c|c|c|}
\hline & Mean & Std. Deviation & $\mathrm{T}$ & $\mathrm{df}$ & Sig. (2-tailed) \\
\hline Post-test experimental group & 86.0000 & 3.60555 & & 20 & 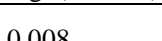 \\
\hline Post-test control group & 75.0000 & 5.00000 & & 29 & 0.008 \\
\hline
\end{tabular}

Post -test control group Post -test experimental group

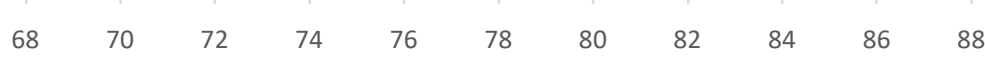

Figure 3. Paired samples statistics test (Post-Test) L2 vocabulary

Table 7 and figure 3 show that there are statistically significant differences in the achievement for the experimental and the control groups in L2 vocabulary. The value of the t-test is (11.00), which is higher than the value of the t-table 
(2.045), at significance statistical level (0.008) less than the value specified (0.05) which indicates that these differences were in favor of the experimental group.

To measure the extent to which the Saudi female EFL learners differ statistically in grasping the linguistic data occurred in the given listening comprehension, Paired Samples Statistics test for the two groups was carried out in posttest. Table 8 indicates the results:

TABLE 8

PAIRED SAMPLES STATISTICS TEST (POST-TEST)

\begin{tabular}{|c|c|c|c|c|c|}
\hline & Mean & Std. Deviation & $\mathrm{T}$ & df & Sig. (2-tailed) \\
\hline Post-test experimental group & 90.80 & 9.31128 & \multirow{2}{*}{-3.693} & \multirow{2}{*}{29} & \multirow{2}{*}{0.021} \\
\hline Post-test control group & 75.60 & 5.12835 & & & \\
\hline
\end{tabular}

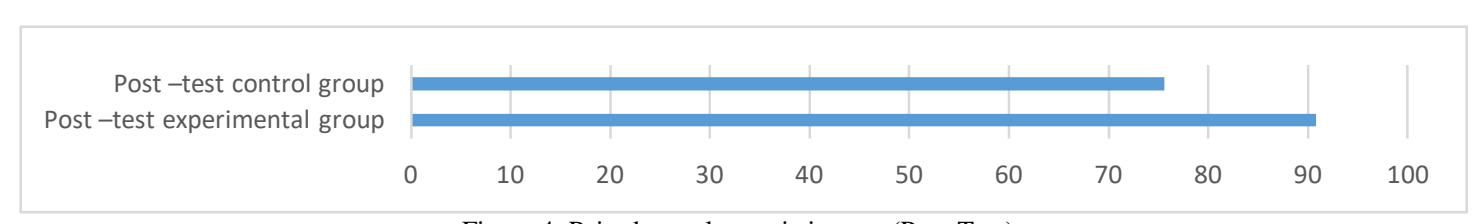

Figure 4. Paired samples statistics test (Post-Test)

Table 8 and the figure 4 show that there are statistically significant differences in the achievement of both the experimental and control groups in grasping the linguistic data occurred in the given listening comprehension. The Ttest value is (3.693), which is higher than the value of the t-table (2.045), at significance statistical level (0.021) less than the value specified (0.05) indicating that these differences were in favor of the experimental group.

To measure whether female EFL learners statistically significant apply different ways of discrimination and guessing of unknown words, Paired Samples Statistics test for the two groups was carried out in Post-Test. Table 9 indicates the results:

TABLE 9

PAIRED SAMPles STATISTICS TEST (POST-TEST) WAYS OF DISCRIMINATION AND GUESSING OF UNKNOWN WORDS

\begin{tabular}{|c|c|c|c|c|c|}
\hline & Mean & Std. Deviation & $\mathrm{T}$ & df & Sig. (2-tailed) \\
\hline Post-test experimental group & 96.00 & 5.29150 & \multirow{2}{*}{7.941} & \multirow{2}{*}{29} & \multirow{2}{*}{0.015} \\
\hline Post-test control group & 74.333 & 6.65833 & & & \\
\hline
\end{tabular}

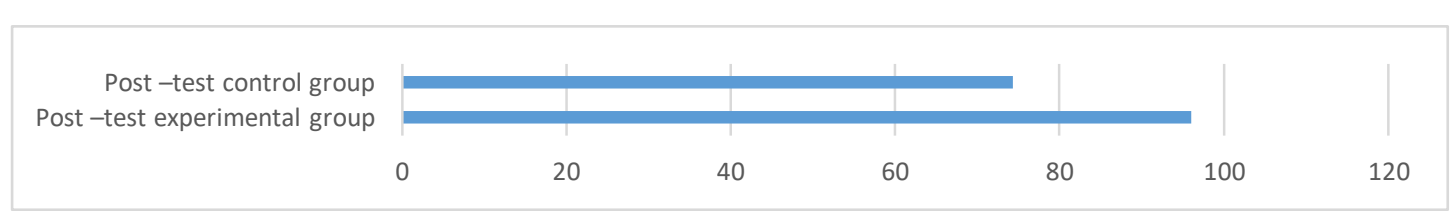

Figure 5. Paired samples statistics test (Post-Test) ways of discrimination and guessing of unknown words

Table 9 and figure 5 show that there are statistically significant differences in the achievement of the experimental and control group in the discrimination and guessing of unknown words. The value of the t-test is (7.941), which is higher than the value of the t-table (2.045), at significance statistical level (0.015) less than the value specified (0.05) indicating that these differences were in favor of the experimental group.

\section{DISCUSSION}

The present study significantly contributes to the literature of examining the listening comprehension among EFL learners in the Saudi context. Its results were in favour of using the audio-visual listening materials which enable Saudi EFL students to realize different cognitive factors of the listening process.

In order to find out the best medium (aural or audio-visual) for the participants, means, standard deviation, skewness, and kurtosis were computed. The mean of the experimental group is $(\mathrm{M}=87.8, \mathrm{SD}=8.8)$ for the pre-test, and ( $\mathrm{M}=93.3$, $\mathrm{SD}=10.1$ ) which show that the exposure to the audio-visual materials is significantly positive. Meanwhile, the means of the control group in the pre-test is $(M=39.3 \mathrm{SD}=15.0)$ and for the post-test is $(M=40.6, \mathrm{SD}=15.8)$, which show that their improvement in the aural material is not really remarkable. In addition, a t-test was carried out and the results show that there is a remarkable difference between the students' scores in the post-test and the pre-test. Means of the experimental group is $(\mathrm{M}=63.0, \mathrm{SD}=27.3)$, while the means of the control group is $(\mathrm{M}=67.0, \mathrm{SD}=29.6), \mathrm{t}(58)=15.1, \mathrm{p}=.000, \mathrm{~d}=12)$. This finding agrees with those of Brett (1997) and assures that the usage of the audio-visual material is more effective than the aural material in term of improving the skills of listening comprehension of Saudi female EFL learners.

The experimental group outperformed the control group in the listening session due to using the audio-visual listening materials. Moreover, the results contributed to answering the question raised by Nyns (1989) "Which medium is best suited to teach such-and-such a skill"? This research proved that audio-visual medium is highly effective in the listening comprehension, unlike the aural one.

\section{A. Research Question 1}


Paired samples statistics test for the two groups (control and experimental) is carried out in Post-test. The experimental group's mean is 86.0000, while the control group's mean is 75.0000. Therefore, the results show that there are statistically significant differences in students' achievement for the control group and experimental group in L2 vocabulary in favour of the experimental group.

No doubt that the experimental group subjects outperformed the control group in both the pre-test and the post-test of listening. The achievement is clear in their capability in recognizing the meaning of variant vocabulary in both tests. They managed to recognize the vocabulary which are confusing to them due to the support of the audio-visual listening means. This result emphasizes the effect of the subjects' knowledge of L2 words, syntax and grammar during the process of both tests. Besides, the results show remarkable differences in the metacognitive capabilities among both groups. The results are compatible with the findings revealed by Bonk (2000), Mecartty (2000), Field (2003), and Zeeland and Schmitt (2013).

The finding is compatible with Nunan's (2001) results that listening is characterized with complexity compared to other linguistic skills. This is attributed to the fact that listening entails other sub-categories like understanding, memorizing and evaluating. For this purpose, knowledge of L2 vocabulary is essential because it enables EFL learners to understand the content of the listening activity. Indeed, knowledge of L2 vocabulary makes listening an easier task. As long as EFL learners can understand the listening content, they can successfully reply to questions pertinent to the listening activity. In such a way, EFL learners will be able to improve their speaking skills as well. Therefore, this finding is compatible as well with Ellis (2005). Saudi female students will be able to improve their ability of proper and correct ways of pronunciation related to various words which they are being taught. They will be able to recognize different sounds that for particular words they are learning. Hence, they will be able to distinguish between different English words. This will lead Saudi female EFL learners to have successful patents in realizing the English-native accents at the long term. They will be also able to differentiate various types of words classes of the same words and their proper ways of pronunciation.

\section{B. Research Question 2}

To measure if female EFL learners statistically significant differ in grasping the linguistic data occurred in the given listening comprehension, paired samples statistics test for the two groups is carried out in post-test. The mean of the experimental group is 90.80 , while the mean of the control group is 75.60 . The results show that there are statistically significant differences in student achievement in control group and experimental in grasping the linguistic data occurred in the given listening comprehension in favour of the experimental group.

In addition, the experimental group subjects were capable to prove their ability in understanding information contained in the listening text unlike the control group. They succeeded in that because of their capability in comprehending the information in the post test. They also managed to response with correct answers to the questions related to the listening comprehension test. The results show the experimental group's capability in controlling the cognitive procedures in the listening session. The results of this study confirm those ones revealed by Goh (2008), and Juffs and Herrington (2011). Anyhow, it is not compatible with the findings revealed by Andringa et al. (2012).

This finding supports findings reported by Bueno et al. (2006) as L2 listening performance includes top-down listening process and bottom-up listening process. The top-down process ensures that Saudi female EFL learners will generally understand various main ideas contained in the listening activity regardless of focusing on the meanings of particular words or certain structures. In addition, the bottom-up process will sustain the ability of Saudi female EFL learners to exploit their L2 linguistic knowledge in understanding the listening comprehension. Their linguistic knowledge is centred on their L2 sounds' background and their familiarity to the L2 vocabulary. For example, Saudi female EFL learners will be able to distinguish different types of phrase structure rules. They will also be able to differentiate between various minimal pairs like bin and pin, fan and van, thin and sin, etc. As such, Saudi female EFL learners will be able to distinguish between various utterances in their attempts to have full understanding of the meaning of the listening activity.

This finding also conforms to those reported by Celce-Murcia (2001) because Saudi female EFL learners should understand structure of English phrases as a means of understanding the spoken text which they are listening to. In this regard, there are expectations that Saudi female EFL learners will practice their background of the L2 to understand different English sounds' units and different boundaries of syllables in their process of identifying words included in the listening activity. This finding will help Saudi female EFL learners memorize and retrieve the retained English words because they have the capability of parsing. At this stage, Saudi female EFL learners will successfully restore new information because they have managed to match them to the old memorized types of information. In this concern, Saudi female EFL learners should adopt either one of these two processes because it is difficult according to CelceMurcia (2001) to carry out the two processes together. Therefore, Saudi EFL learners must have a pre-idea of what they will listen to, so that they can avoid making inferences according to their background knowledge, but instead understanding the new information. Therefore, Saudi female EFL learners will be able to define the end of words because they can identify the sound units which form the speech stream. They will also be able to overcome the difficulty of defining word boundaries, particularly those L2 stress patterns which differ from those of the Arabic language. Thus, Saudi female EFL learners will be able to analyse, evaluate facts and causes contained in the listening text. 


\section{Research Question 3}

Paired samples statistics test was carried out to measure whether both groups apply different ways of discrimination and guessing of unknown words in post-test. The experimental group's mean is 96.00 , while the control group's mean is 74.333. Thus, the results show that there are remarkable differences in students' achievement for both groups (control group and experimental group) in ways of discrimination and guessing of unknown words. According to the results, experimental group outperformed the control group in a notable way.

The multimedia listening means assisted the subjects of the experimental group to succeed in distinguishing L2 vocabulary like the minimal pairs, unlike the control group. This result is compatible with the results revealed by Goh (2008), and Wilson, et al. (2011).

This finding is compatible with those of Brett (1997). The finding proved that multimedia is effective in enhancing the skills of listening comprehension of Saudi female EFL learners. The experimental group was better in the listening performance than the control group because of the privileges of the audio-visual listening. The finding helps to answer the question raised by Nyns (1989) "Which medium is best suited to teach such-and-such a skill"? The present study proved that multimedia listening comprehension led to better results in the listening comprehension in comparison to aural listening comprehension. This was evident as multimedia enabled experimental group to recall missing words. The present study also affirms the efficiency of multimedia materials to the listening comprehension skills of Saudi female EFL participants. This is attributed to the fact that multimedia comprises different components of visual and aural inputs, written tasks and providing feedbacks to learners' responses.

\section{IMPLICATIONS AND CONCLUSION}

This study focused on the effect of audio and audio-visual materials on listening acquisition among EFL students. The results showed that audio-visual has significant effect at the level of Listening acquisition among EFL Students. They indicated that there were statistically significant differences in favour of the experimental group. The post-test proved a significant improvement in the performance of the students of the experimental group which audio-visual has been applied to them and surpassed the control group that underwent audio program. Therefore, the study concluded that the teaching using audio-visual has a higher level of effectiveness in aural listening comprehension materials.

Achievements of Saudi female EFL students in both tests, the pre-test and the post-test, were clearly connected to the use of the multimedia listening means rather than being connected to the audial listening means. In fact, that is because the participants were anticipating hearing the spoken text without intervention even if they don't understand the listening comprehension. On the other hand, the audio-visual listening means provide interaction with the learners because they can see and recognize the setting and the whole information of the listening comprehension.

The Saudi female EFL subjects were encountering some frequent obstacles while using both listening means the audio-visual and the aural one. The obstacles entail comprehending the speech and the text completely since they are supposed to understand the whole listening activities from all aspects. All the obstacles that interrupt the process of understanding the listening comprehension should be worked out by the L2 instructors. The L2 teachers should encourage the L2 students to listen carefully and thoroughly.

The Saudi female EFL students should be instructed to concentrate on the sounds of the words, vocabulary and the use of common discourse markers like 'anyway', 'ok', 'right', 'so', etc. Furthermore, they should be instructed to focus on the basic information and the main ideas existed in the speech. The Saudi female EFL students should also know the perfect way to improve the top-down comprehension from the spoken text. In addition, they should be instructed to relate the information from the given speech to the source of knowledge they came from. Thus, it is recommended for the Saudi EFL teachers to use the audio-visual teaching method to improve the learners' perception towards listening tasks. No doubt that the audio-visual listening means help Saudi female EFL students in concentrating perfectly since they display the gestures of the characters, and the whole setting that provide the learners with a wide knowledge of the situation and simplify the process of recognition.

Therefore, it is crucial for the Saudi EFL teachers to know the complicated identity of listening comprehension in order to bring the suitable tasks for the students. This clarification agrees with results of this thesis that there are remarkable differences between the control and the experimental group in the process of listening by choosing both methods (the aural or the audio-visual one). So, it is clearly successful to teach L2 listening comprehension through audio-visual means more than the aural one.

This study contributes to benefit researchers and practitioners who care about L2 listening comprehension gain from aural versus audio-visual inputs for EFL students. The rapid development in the field of information technology and its multiple uses in education require to think about how to adapt the means and methods of education to be compatible with the nature of technological development in the methods of education, especially after the increasing need for education in the information technology environment. Dealing with these technologies, would raise the level of participatory, interactive and motivation among students.

The present study also significantly contributes to the general policy of the ministry of education and that of Najran University that aim to develop the linguistic skills of the Saudi EFL learners. Educational and academic authorities should hold training courses for teachers especially on the use of audio-visual activities in the classroom. Finally, 
further research can be conduct on the use of audio-visual in teaching, especially with regard to the impediments of applying this method in education.

\section{ACKNOWLEDGEMENTS}

The authors would like to express their gratitude to the Ministry of Education and the Deanship of Scientific Research, Najran University, Kingdom of Saudi Arabia, for their financial and technical support under code number NU/-/SEHRC/10/1117.

\section{REFERENCES}

[1] Andringa, S., Olsthoorn, N., van Beuningen, C., Schoonen, R., \& Hulstijn, J. (2012). Determinants of success in native and non-native listening comprehension: An individual differences approach. Language Learning, 62(S2), 49-78. https://doi.org/10.1111/j.1467-9922.2012.00706.x

[2] Bacon, S. M. (1992). The relationship between gender, comprehension, processing strategies and cognitive and affective response in foreign language learning. Modern Language Journal, 76 (2), 160-178. https://doi.org/10.1111/j.15404781.1992.tb01096.x

[3] Bonk, W. (2000). Second language lexical knowledge and listening comprehension. International Journal of Listening, 14(1), 14-31. https://doi.org/10.1080/10904018.2000.10499033

[4] Brett, P. (1995). Multimedia for listening comprehension: The design of a multimedia-based resource for developing listening skills. System, 23(1), 77-86. https://doi.org/10.1016/0346-251X(94)00054-A

[5] Brett, P. (1997). A comparative study of the effects of the use of multimedia on listening comprehension. System, 25(1), $39-53$. https://doi.org/10.1016/S0346-251X(96)00059-0

[6] Buck, G. (2001). Assessing Listening. UK: Cambridge University Press.

[7] Bueno, A, Madrid, D. \& McLaren, N. (2006). TEFL in Secondary Education. Granada: Editorial Universidad de Granada. http://www.editorialugr.com/

[8] Celce-Murcia, M., \& Olshtain, E. (2000). Discourse and context in language teaching: A guide for language teachers. Cambridge: Cambridge University press.

[9] Celce-Murcia, M. (2001). Teaching English as Second or Foreign Language. United States of America: Thomson Learning, Inc.

[10] Dunkel, P. (1991). Listening in the native and second/foreign language: Toward an integration of research and practice. TESOL Quarterly, 25(3), 431-457. https://doi.org/10.2307/3586979

[11] Ellis, R. (2005). Principles of instructed language learning. System, 33(2), $209-224$. https://doi.org/10.1016/j.system.2004.12.006

[12] Field, J. (2002). The changing face of listening. In J. Richards \& W. Renandya (eds.), Methodology in language teaching: An anthology of current practice, (pp. 242- 247). Cambridge: Cambridge University Press.

[13] Field, J. (2003). Promoting perception: Lexical segmentation in second language listening. ELT Journal, 57(4), 325-334. https://doi.org/10.1093/elt/57.4.325

[14] Goh, C. (2008). Metacognitive Instruction for Second Language Listening Development: Theory, Practice and Research Implications. Sage Publications, pp. 188- 213.

[15] Graham, S. \& Macaro, E. (2008). Strategy Instruction in Listening for Lower-Intermediate Learners of French. Language Learning, 58(4), $747-783$

[16] Juffs, A., \& Harrington, M. (2011). Aspects of working memory in L2 learning. Language Teaching, 44(2), $137-166$. https://doi.org/10.1017/S0261444810000509

[17] Lever-Duffy, J. (2003). Teaching and Learning with Technology. USA: Pearson Education Inc.

[18] Lynch, T. \& Mendelsohn, D. (2002). Listening. In N. Schmitt (Ed.), An introduction to applied linguistics (pp. 193-210). London: Arnold.

[19] Mayer, R. E. (2001). Multimedia learning: Are we asking the right questions? Educational Psychologist, 32(1), 1-19.

[20] Mayer, R. E. (2009). Multimedia learning (2nd ed). New York: Cambridge University Press.

[21] Mecartty, F. (2000). Lexical and grammatical knowledge in reading and listening comprehension by foreign language learners of Spanish. Applied Language Learning, 11(2), 323-348.

[22] Nunan, D. (1992). Research Method in Language Learning. UK: Cambridge University Press.

[23] Nunan, D. (2001). Second language teaching and learning. Boston: Heinle and Heinle.

[24] Nushi, M. \& Orouji, F. (2020). Investigating EFL Teachers' Views on Listening Difficulties Among Their Learners: The Case of Iranian Context. SAGE Open April-June 2020, 10- 16. https://doi.org/10.1177/2158244020917393

[25] Nyns, R. R. (1989) Is intelligent computer-assisted language learning possible? System, 17(1), 35-47. https://doi.org/10.1016/0346-251X(89)90058-4

[26] Rogers, C. V., \& Medley, F. W., Jr. (1988). Language with a purpose: Using authentic materials in the foreign language classroom. Foreign Language Annals, 21, 467-478. https://doi.org/10.1111/j.1944-9720.1988.tb01098.x

[27] Rost, M. (2002). Teaching and researching listening. London: Longman.

[28] Scarcella, R. C., \& Oxford, R. L. (1992). The tapestry of language learning: The individual in the communicative classroom. Boston, MA: Heinle \& Heinle.

[29] Staehr, L. S. (2009). Vocabulary knowledge and advanced listening comprehension in English as a foreign language. Studies in Second Language Acquisition, 31(4), 577-607. https://doi.org/10.1017/S0272263109990039

[30] Underwood, M. (1990). Teaching listening. Longman: Harlow.

[31] Vandergrift, L \& Cross, J. (2018). Learning to listen versus listening to learn. In John I. Liontas (ed). The TESOL Encyclopedia of English Language Teaching (pp. 1- 16). John Wiley \& Sons, Inc. 
[32] Vandergrift, L. \& Baker, S. (2015). Learner variables in second language listening comprehension: An exploratory path analysis. Language learning, 65(2), 390-416. https://doi.org/10.1111/lang.12105

[33] Vandergrift, L. \& Goh C. C. M. (2012). Teaching and Learning Second Language Listening: Metacognition in Action. Routledge.

[34] Wilson, I., Kaneko, E., Lyddon, P., Okamoto, K., \& Ginsburg, J. (2011). Nonsense-syllable sound discrimination ability correlates with second language (L2) proficiency. In W.-S. Lee \& E. Zee (Eds.), Proceedings of the $17^{\text {th }}$ International Congress of Phonetic Sciences (pp. 2133-2136). Hong Kong: City University of Hong Kong.

[35] Zeeland, H. \& Schmitt, N. (2013). Incidental vocabulary acquisition through L2 listening: A dimensions approach. System $41(3), 609-624$.

Anwar A. H. Al-Athwary is currently an associate professor at Najran University, KSA. He received his M.A. in Linguistics from Jawaharlal Nehru University, India. He got his PhD in linguistics from Aligarh Muslim University, India. His special areas of interest are lexical borrowing, phonetics and phonology, and linguistic landscape.

Nada M. Lasloum is an MA scholar at Department of English, College of languages and Translation, Najran University, KSA. She got her BA in English from Najran University, KSA. Her main interests of research are anthropology, applied linguistics and translation. 